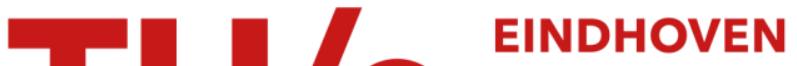

\section{Measurements of electric-field strengths in ionization fronts during breakdown}

Citation for published version (APA):

Wagenaars, E., Bowden, M. D., \& Kroesen, G. M. W. (2007). Measurements of electric-field strengths in ionization fronts during breakdown. Physical Review Letters, 98(7), 075002-1/4. [075002].

https://doi.org/10.1103/PhysRevLett.98.075002

DOI:

10.1103/PhysRevLett.98.075002

Document status and date:

Published: 01/01/2007

\section{Document Version:}

Publisher's PDF, also known as Version of Record (includes final page, issue and volume numbers)

\section{Please check the document version of this publication:}

- A submitted manuscript is the version of the article upon submission and before peer-review. There can be important differences between the submitted version and the official published version of record. People interested in the research are advised to contact the author for the final version of the publication, or visit the $\mathrm{DOI}$ to the publisher's website.

- The final author version and the galley proof are versions of the publication after peer review.

- The final published version features the final layout of the paper including the volume, issue and page numbers.

Link to publication

\section{General rights}

Copyright and moral rights for the publications made accessible in the public portal are retained by the authors and/or other copyright owners and it is a condition of accessing publications that users recognise and abide by the legal requirements associated with these rights.

- Users may download and print one copy of any publication from the public portal for the purpose of private study or research.

- You may not further distribute the material or use it for any profit-making activity or commercial gain

- You may freely distribute the URL identifying the publication in the public portal.

If the publication is distributed under the terms of Article 25fa of the Dutch Copyright Act, indicated by the "Taverne" license above, please follow below link for the End User Agreement:

www.tue.nl/taverne

Take down policy

If you believe that this document breaches copyright please contact us at:

openaccess@tue.nl

providing details and we will investigate your claim. 


\title{
Measurements of Electric-Field Strengths in Ionization Fronts during Breakdown
}

\author{
E. Wagenaars, ${ }^{1}$ M. D. Bowden, ${ }^{2}$ and G. M. W. Kroesen ${ }^{1, *}$ \\ ${ }^{1}$ Department of Applied Physics, Eindhoven University of Technology, P.O. Box 513, 5600 MB Eindhoven, The Netherlands \\ ${ }^{2}$ Department of Physics and Astronomy, The Open University, Milton Keynes, MK7 6AA, United Kingdom
}

(Received 3 October 2006; published 14 February 2007)

\begin{abstract}
Using laser-induced fluorescence-dip Stark spectroscopy, we performed time-resolved, direct measurements of electric-field strengths during the breakdown phase of a low-pressure, pulsed discharge in xenon. With this experimental technique we could for the first time quantitatively measure the time evolution of the driving force of the plasma breakdown process: the electric field. Moving ionization fronts were measured with submicrosecond resolution. These ionization fronts were sustained by a spatially narrow, rapidly moving region of strong electric field.
\end{abstract}

DOI: 10.1103/PhysRevLett.98.075002

PACS numbers: 52.80.Dy, 51.50.+v, 52.38.Dx

In this Letter we report time-resolved, direct measurements of electric-field strengths in ionization fronts during breakdown. To our knowledge, this is the first time that such measurements have been performed, opening up possibilities for detailed studies of breakdown processes in a wide variety of man-made discharges both at low and high pressure. Additionally, our understanding of natural discharge phenomena like lightning and sprites can directly benefit from such electric-field measurements.

Breakdown processes, including ionization fronts, have been studied in detail in many contexts in the past, for instance, the ignition phases of high-intensity discharge lamps [1], fluorescent lamps [2], plasma display panels [3], air purification with corona discharges [4], and dielectric barrier discharges [5]. However, most of these studies were modeling investigations and there are few direct measurements of the plasma properties of ionization fronts in breakdown. Experimental investigations are challenging mainly due to the highly transient nature of breakdown. Additionally, the diagnostics available for direct measurements of plasma parameters such as charge densities and electric-field strengths are experimentally complex. Some examples of experimental research on breakdown for specific plasma applications are cross-correlation spectroscopy of dielectric barrier discharges [6], optical and electrostatic investigations of igniting fluorescent tubes [7], and investigations of electric fields in streamers, using the Kerr effect [8]. While these are notable studies, plasma properties were obtained indirectly from measurements of emission [6,7] or via a model interpretation [8]. There is a lack of direct experimental data on the plasma properties of ionization fronts.

The driving force of ionization fronts is the electric field. Electrons in the discharge gap gain energy in the electric field and cause ionization avalanches. Additionally, due to the electric-field ions drift towards the cathode, causing secondary electron emission and new avalanches. Furthermore, the accumulated charges produced in the avalanches cause space charge fields, which modify the applied electric field, influencing the development of sub- sequent avalanches. Detailed knowledge of the electricfield distribution, including its time evolution, is crucial for understanding the rapid, transient processes that occur during breakdown.

Recently, we developed an experimental method for measuring electric-field distributions in low-pressure xenon gas. These measurements were performed using laser spectroscopy of neutral gas atoms. Our technique can be used both in neutral gas and plasmas, making it suitable to study breakdown processes in pulsed discharges. Details of this diagnostic can be found in [9]; here we will only describe its main features. The method is based on measuring Stark effects in Rydberg levels of atoms by laserinduced fluorescence-dip spectroscopy. This technique was introduced by Czarnetzki et al. [10] for investigations in atomic hydrogen. Later, it has been applied in argon discharges [11,12].

Figure 1 shows the excitation scheme used in our investigations. Ground state xenon atoms were excited to the $6 p[1 / 2]_{0}$ state in a 2-photon transition at $249.629 \mathrm{~nm}$. Using an intensified charge-coupled device (ICCD) camera with an interference filter, we observed fluorescence light at $828.2 \mathrm{~nm}$ resulting from the decay of $6 p[1 / 2]_{0}$ to $6 s[3 / 2]_{1}$ states. A second laser was tuned to probe transitions from the intermediate $6 p[1 / 2]_{0}$ state to the highlying Rydberg $15 d[3 / 2]_{1}$ level. Excitation of this transition was detected as a decrease (dip) in the fluorescence intensity.

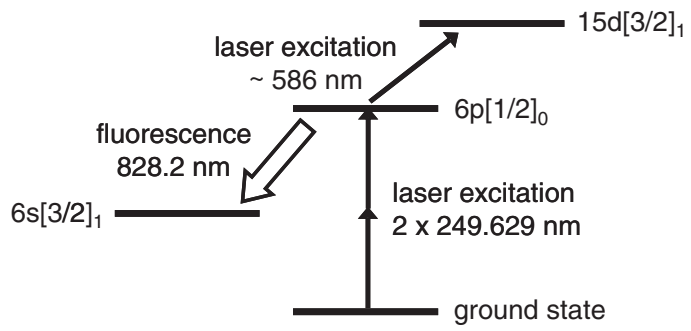

FIG. 1. Excitation scheme for laser-induced fluorescence-dip Stark spectroscopy in xenon. 
The lasers used in this excitation scheme were both pulsed, tunable dye lasers pumped by the same Nd:YAG laser. The energies of the lasers were reduced to a few hundred $\mu \mathrm{J}$ to avoid saturation effects of the atomic transitions.

We studied breakdown in a pulsed discharge between parabolic electrodes in low-pressure xenon gas. In our earlier, more indirect, observations of breakdown phenomena this discharge was investigated for an argon environment using optical emission imaging with an ICCD camera [13,14].

Both laser beams were directed to the electrode arrangement inside the vacuum vessel where they overlapped each other in between the tips of the electrodes as shown in Fig. 2. A cylindrical lens focused the first laser, operating at $249.629 \mathrm{~nm}$, to a sheet parallel to the discharge axis, with a cross section of $1.0 \times 0.15 \mathrm{~mm}$. The second laser, with a wavelength around $586 \mathrm{~nm}$, remained unfocused with a diameter of about $2 \mathrm{~mm}$. Perpendicular to the laser beams, a lens system including an interference filter imaged the fluorescence light onto an ICCD camera. The signal from a single ICCD bin was monitored during a laser scan. In this ICCD bin, fluorescence light was accumulated from a volume of about $0.15 \times 0.5 \times 0.15 \mathrm{~mm}$ located on the discharge axis between the electrodes, $0.5 \mathrm{~mm}$ in front of the cathode. The measurement volume was determined by the focus of the first laser, the lens system imaging the fluorescence light, and the pixel size of the ICCD camera.

The discharge system consisted of two cylindrically symmetric electrodes of which the tips had a radius of curvature of $4 \mathrm{~mm}$. They were mounted inside a vacuum chamber creating a $3.3 \mathrm{~mm}$ discharge gap. The vacuum vessel was filled with xenon gas at a pressure of $600 \mathrm{~Pa}$. A pulsed discharge was created by applying voltage pulses to the electrodes. These pulses had a rise time of $30 \mu \mathrm{s}$, a total duration of $100 \mu \mathrm{s}$, a repetition rate of $500 \mathrm{~Hz}$, and an amplitude of $390 \mathrm{~V}$, which was about $15 \%$ above the breakdown voltage. Figure 3 shows ICCD images of the breakdown phase of the discharge, using an exposure time of $100 \mathrm{~ns}$. In these measurements all the light from the discharge in the wavelength range $350-850 \mathrm{~nm}$ was directly imaged onto the ICCD camera. The images show characteristic features of breakdown: first, a region with light emission in front of the anode $(t=26.0 \mu \mathrm{s})$.

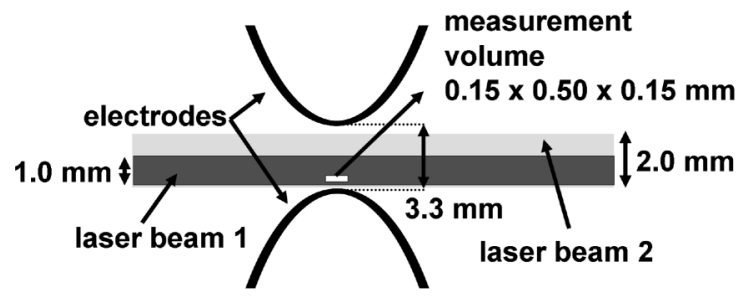

FIG. 2. Schematic diagram of the electrode arrangement, including both laser beams. Laser beam 1 was focused into a sheet parallel to the discharge axis, while beam 2 remained unfocused.
Subsequently, the light emission became more intense and crossed the electrode gap $(t=27.5 \mu \mathrm{s})$. This moving light front was previously identified as an ionization front $[13,14]$. Finally, the discharge stabilized, covering the cathode surface $(t=40.0 \mu \mathrm{s})$.

The Stark effects were measured from experimental spectra by determining the shifts of the $15 d[3 / 2]_{1}$ Rydberg level. These observed Stark shifts were correlated to electric-field strengths by comparison with a theoretical calculation $[9,15]$.

The laser scan for a single electric-field measurement consisted of 8000 laser shots which took about 13 minutes. A full experiment, measuring the time evolution of electric-field strengths during the breakdown phase of the discharge, lasted for about 6 hours. During this period, the timing of the discharge onset slowly drifted to a maximum offset of $1.5 \mu \mathrm{s}$ at the end of the measurement series. To compensate for this drift, calibration of the timing of the laser experiments relative to the breakdown events was done by taking reference ICCD images of the plasma light emission before each laser scan. With this procedure an absolute timing accuracy of about $150 \mathrm{~ns}$ was achieved for each electric-field measurement.

Figure 4 shows the experimental results: measurements of electric fields during the breakdown phase of the discharge together with the measured electrode voltage, current, and plasma light emission. The measurements show a clear peak in electric field at the time when the ionization front crosses the measurement volume $(t=27.0 \mu \mathrm{s})$. Before this time $(t=0-25 \mu \mathrm{s})$, the measured electric field corresponds to the applied potential across the electrodes. After the crossing of the ionization front $(t=28-40 \mu \mathrm{s})$, there remains a significant electric field inside the electrode gap.

At the time of the enhanced electric field $(t=$ 26.0-28.0 $\mu \mathrm{s}$ ), a current of a few mA started to develop, and the electric field in the gap increased sharply in a period of $200 \mathrm{~ns}$, to a value of $1600 \mathrm{~V} / \mathrm{cm}$. This was an enhancement of the electric field of about 50\% compared to the applied electric field. The field then decreased very
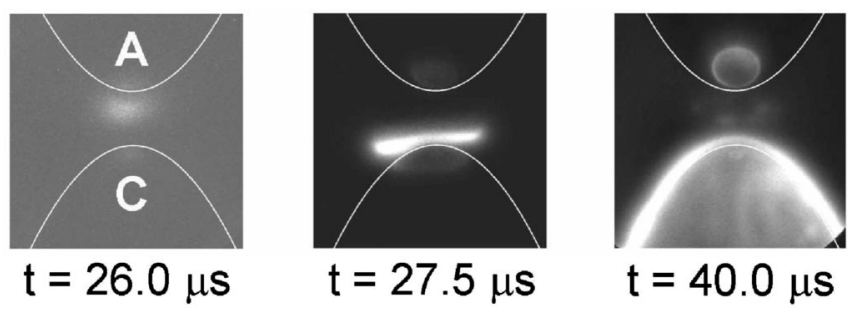

FIG. 3. ICCD emission images of breakdown. The top electrode was the anode, the bottom electrode the grounded cathode. Light from 7500 discharges was accumulated for each image. The white lines indicate the edges of the electrodes. The spot of light on the anode in the image $t=40.0 \mu \mathrm{s}$ was not direct plasma emission, but a reflection of the plasma around the cathode. 

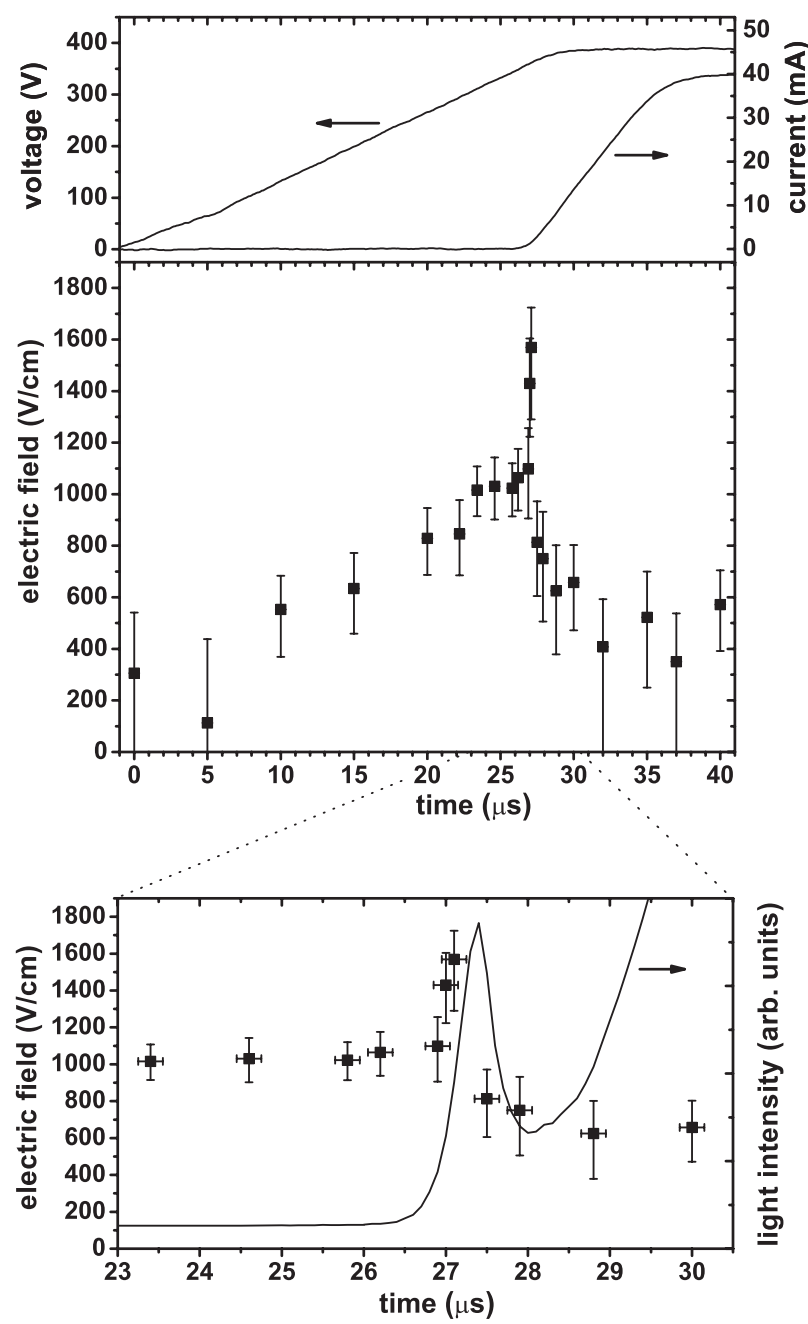

FIG. 4. Experimental results. The top graph shows the measured voltage and current waveforms of the discharge. In the middle graph electric-field strengths, measured $0.5 \mathrm{~mm}$ in front of the cathode, are presented. The bottom graph shows a magnification of the middle graph for times between 23 and $30 \mu \mathrm{s}$ and the observed light emission from the discharge, originating from the same volume as the fluorescence light in the laser experiments.

rapidly to $800 \mathrm{~V} / \mathrm{cm}$ at $t=27.5 \mu \mathrm{s}$. The measurements indicate that the moving ionization front observed in emission is sustained by a spatially narrow, rapidly moving region of strong electric field.

The observed enhancement of the electric field in the gap is caused by a positive space charge region in front of the anode as a result of ions produced in electron avalanches. This space charge region modifies the potential in the gap, increasing the electric field between the cathode and the space charge region and decreasing the field towards the anode. The continuing electron avalanches in the high-field region cause a further extension of the space charge region into the gap. This is observed as a moving region of enhanced electric field in front of the space charge, followed by a decrease of electric field inside the space charge region. In the high-field region, electron avalanches cause considerable ionization and excitation of atoms. This results in observable light emission since the lifetime of excited xenon is of the order of tens of nanoseconds. In the low-field region, there is less excitation and light emission. Therefore, the ionization front is also observed as a sharp light front crossing the electrode gap.

From the comparison of the timing of the electric-field front and the light front, presented in the bottom graph of Fig. 4, it is clear that the electric-field front was narrower and moved ahead of the light front by about $300 \mathrm{~ns}$. These differences can be explained by the time needed for electrons to gain energy in the electric field, excite a xenon atom, and the subsequent decay of this atom, resulting in light emission. Since these processes have durations of the order of tens to a few hundred nanoseconds, the light emission will be delayed relative to the electric field. Additionally, due to the statistical nature of these processes, the emitted light will be spatially more spread out than the electric-field front, leading to a broader light front. These investigations show that by measuring the time evolution of electric-field distribution in addition to light emission we can get more detailed information on the duration and timing of the ionization front.

From the rise time of the electric-field enhancement, shown in Fig. 4, we can estimate the (average) speed of the moving ionization front to be of the order of $10^{4} \mathrm{~m} / \mathrm{s}$. This is in reasonable agreement with the speed calculated from the plasma light emission data, which gives a velocity of the order of $5 \times 10^{3} \mathrm{~m} / \mathrm{s}$. The resolution of our electricfield measurements was about $150 \mathrm{~V} / \mathrm{cm}$ for fields above $400 \mathrm{~V} / \mathrm{cm}$. For lower fields, the Stark shifts are less sensitive to electric field; therefore, the resolution was lower, about $350 \mathrm{~V} / \mathrm{cm}$.

During the period $t=28-40 \mu \mathrm{s}$, after the ionization front crossed the electrode gap, the electric field stabilized at low values around $500 \mathrm{~V} / \mathrm{cm}$, while the current reached a maximum of $40 \mathrm{~mA}$, as seen from Fig. 4. The uncertainties in the electric-field measurements in this region were considerable since the resolution of our diagnostic was limited for low electric fields. Nevertheless, a significant electric field was measured during this period, indicating that the development of a single ionization front in the gap was not sufficient for full breakdown and the discharge continued to develop after this time.

Figure 5 shows a schematic interpretation of our explanation of the effect of the first ionization front on the potential distribution in the discharge gap. Before the ionization front occurs, the potential in the gap is linear, when small deviations $(<15 \%)$ due to the curvature of the electrodes are neglected. The buildup of positive space charge in front of the anode leads to (partial) shielding of the anode. The space charge region develops into an ionization front that crosses the discharge gap, extending part 


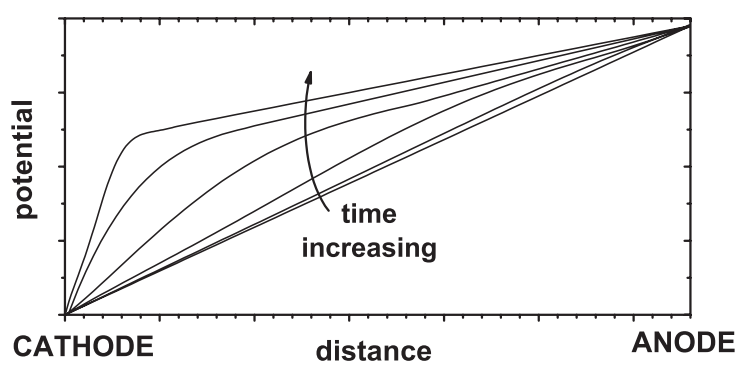

FIG. 5. Schematic interpretation of the evolution of the potential in the gap during the crossing of the ionization front. The potential distribution in the gap starts with a linear profile from the applied voltage. Crossing of the ionization front modifies the potential distribution, resulting in the development of a cathode sheath region.

of the anode potential further into the gap. However, the ionization front does not shield the full anode potential. After the ionization front crossed the gap, most of the potential drop is located near the cathode, in a (developing) sheath region, but there is still a significant potential difference between this sheath region and the anode. In this region the breakdown process continues and only after $t=$ $45 \mu \mathrm{s}$, the modification of the potential in the gap is completed and a stable glowlike discharge is formed.

In summary, we have shown for the first time that it is possible to directly measure time-dependent electric-field strengths in an ionization front during breakdown. We measured electric fields between 0 and $1600 \mathrm{~V} / \mathrm{cm}$ with a resolution of $150-350 \mathrm{~V} / \mathrm{cm}$, depending on the magnitude of the electric field. Previous measurements have shown breakdown to be characterized by an ionization front crossing the discharge gap. These new measurements show that this ionization front is sustained by a spatially narrow, rapidly moving region of strong electric field. It caused an enhancement of the electric field in the gap of about $50 \%$, relative to the applied electric field. Our measurements show that the first ionization front did not completely change the potential distribution to that of a selfsustained discharge; the development towards a steadystate situation continued.

The presented experimental technique provides a useful tool for future investigations of breakdown. By using an excitation scheme with a higher Rydberg level, we can increase the sensitivity of our technique in low electric fields [9]. This allows a more detailed study of the pro- cesses occurring after the first ionization front. Second, the technique can be used to study a wide variety of different low-pressure discharges with both spatial and temporal resolution, for instance, ignition processes in rf processing plasmas, plasma display panels, and discharge lamps. Furthermore, an extension of the technique to higher pressures opens up the possibility to gain understanding of streamer breakdown processes occurring in corona discharges and dielectric barrier discharges. This will also directly affect our knowledge on natural discharges such as lightning and sprites.

This research was supported by the Dutch Technology Foundation STW, applied science division of NWO and the Technology Program of the Ministry of Economic Affairs (No. ETF 5856).

*Electronic address: g.m.w.kroesen@tue.nl

[1] B. Lay et al., Plasma Sources Sci. Technol. 12, 8 (2003).

[2] W. J. M. Brok et al., J. Phys. D: Appl. Phys. 36, 1967 (2003).

[3] J. P. Boeuf, J. Phys. D: Appl. Phys. 36, R53 (2003).

[4] Electrical Discharges for Environmental Purposes: Fundamentals and Applications, edited by E. M. v. Veldhuizen (Nova Science, Huntington, 2000).

[5] U. Kogelschatz, Plasma Chem. Plasma Process. 23, 1 (2003).

[6] K. V. Kozlov et al., J.Phys. D: Appl. Phys. 34, 3164 (2001).

[7] M.F. Gendre et al., Proceedings of the XXVII International Conference on Phenomena in Ionized Gases (Eindhoven University of Technology, Eindhoven, 2005), pp. 13-345.

[8] G.S. Sarkisov, N.D. Zameroski, and J.R. Woodworth, J. Appl. Phys. 99, 083304 (2006).

[9] E. Wagenaars, G. M.W. Kroesen, and M.D. Bowden, Phys. Rev. A 74, 033409 (2006).

[10] U. Czarnetzki, D. Luggenhölscher, and H. F. Döbele, Phys. Rev. Lett. 81, 4592 (1998).

[11] K. Takizawa, K. Sasaki, and K. Kadota, Jpn. J. Appl. Phys., Part 2 41, L1285 (2002).

[12] E. V. Barnat and G. A. Hebner, Appl. Phys. Lett. 85, 3393 (2004).

[13] E. Wagenaars, M.D. Bowden, and G. M.W. Kroesen, Plasma Sources Sci. Technol. 14, 342 (2005).

[14] E. Wagenaars et al., J. Phys. D: Appl. Phys. 39, 3831 (2006).

[15] D. E. Kelleher and E. B. Saloman, Phys. Rev. A 35, 3327 (1987). 